\title{
GERMINAÇÃO E VIGOR DE SEMENTES DE MELANCIA COM DIFERENTES PLOIDIAS SUBMETIDAS ATRATAMENTOS PRÉ-GERMINATIVOS ${ }^{1}$
}

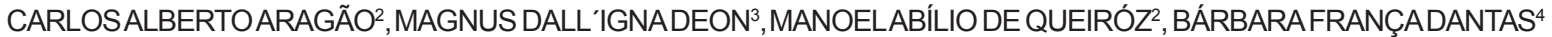

\begin{abstract}
RESUMO - Sementes triplóides e tetraplóides de melancia apresentam problemas de germinação, havendo a necessidade do emprego de tratamentos visando minimizar este problema. Técnicas para melhorar a germinação são importantes para aumentar o potencial de desempenho das sementes e, por conseguinte, a uniformidade das plantas em condições de campo. O presente trabalho teve como objetivo verificar o efeito de tratamentos pré-germinativos em sementes diplóides, triplóides e tetraplóides de melancia. As sementes foram submetidas à maceração; escarificação mecânica + ácido giberélico $\left(\mathrm{GA}_{3}\right)$; escarificação; ácido giberélico $\left(\mathrm{GA}_{3}\right)$. Após a aplicação dos tratamentos, as sementes foram colocadas para germinar em rolos de papel germitest embebido com água destilada na proporção de 2,5 vezes seu peso e mantidas em germinador à temperatura de $25^{\circ} \mathrm{C}$. Foram realizadas avaliações de porcentagem de germinação e crescimento de plântulas aos 5 e 12 dias. A avaliação da emergência de plântulas foi realizada no interior de uma casa-de-vegetação coberta com sombrite $50 \%$, em bandejas plásticas com solo. Foram realizadas contagens diárias do número de plântulas emergidas até a estabilização da emergência das mesmas, considerando-se emergidas aquelas que apresentavam os cotilédones expostos. Foram determinadas as porcentagens de emergência e o índice de velocidade de emergência de plântulas. Apesar dos tratamentos prégerminativos empregados nos três tipos de sementes não serem eficientes no aumento da germinação e emergência de plântulas de melancia, observou-se que o $\mathrm{GA}_{3}$ e a escarificação, empregados separadamente e em associação, promoveram maior crescimento de plântulas oriundas de sementes diplóides e tetraplóides e que a maceração também contribuiu para maior crescimento de plântulas tetraplóides.
\end{abstract}

Termos para indexação: Citrullus lanatus, fitorregulador, estabelecimento de plântulas.

\section{GERMINATIONAND VIGOR OF WATERMELON SEEDS WITH DIFERENT PLOIDIAS SUBMITTED TO PRE-GERMINATIVE TREATMENTS}

\begin{abstract}
Triploid and tetraploid watermelon seeds have low germination and, as such, need seed treatments to alleviate this problem. Techniques to improve seed germination are important factors to increase seed potential and stand uniformity in the field. The objective of this study was to evaluate the effects of pre-germinative treatments in diploid, triploid and tetraploid watermelon seeds. The seeds were subjected to the treatments: control, maceration, mechanical scarification, gibberellic acid $\left(\mathrm{GA}_{3}\right)$ and mechanical scarification $+\mathrm{GA}_{3}$. After the treatments, the seeds were sown in rolls of germination paper imbibed in distilled water in a 2:5 proportion (w:v), and germinated at $25^{\circ} \mathrm{C}$ in germination chambers. Germination percentage and seedling growth were evaluated after 5 and 12 days. Seedling emergence was evaluated in a 50\% shaded green house in trays filled with soil. The daily counting of seedling emergence were carried out until emergence stabilization, to determine the emergence percentage and emergence speed index. Although the pre-germinative
\end{abstract}

\footnotetext{
${ }^{1}$ Submetido em 01/05/2005. Aceito para publicação em 26/07/2006;

${ }^{2}$ Eng. Agrônomo, Dr., Professor Adjunto, Departamento de Tecnologia e Ciências Sociais, DTCS/UNEB, Juazeiro-BA, carlosaragao@hotmail.com;

${ }^{3}$ Eng. Agrônomo, Departamento de Tecnologia e Ciências Sociais, DTCS/
}

UNEB, Juazeiro - BA;

${ }^{4}$ Eng. Agrônoma, Dra., Pesquisadora, Embrapa Semi-Árido, CPATSA, Petrolina - PE, bárbara@cpatsa.embrapa.br. 
treatments did not improve germination and emergence of all the seeds evaluated, it was observed that gibberellic acid and scarification, separately and associated, promoted high seedling growth derived from diploid and tetraploid seeds and also maceration improved tetraploid seedling growth.

Index terms: Citrullus lanatus, plant regulator, seedling establishment.

\section{INTRODUÇÃO}

A melancia, Citrullus lanatus (Thunb) Mansf., é cultivada em vários países do mundo, sendo sua produção mundial de, aproximadamente, 23 milhões de toneladas de frutos. Segundo a FAO (2002), no Brasil, a melancia ocupa área de 82.000ha, com volume de produção de $620.000 t$ e produtividade média de 7,56t.ha ${ }^{-1}$. Entre os maiores produtores estão os estados de SP, RS, BA, GO e TO.

Nos últimos anos, tem-se observado o crescimento da participação das cultivares sem sementes no mercado de melancia. Nos Estados Unidos, até 1991, a melancia sem sementes ocupava cerca de $5 \%$ do mercado, com potencial para atingir de 15 a 50\%. Atualmente, estima-se que o mercado da melancia sem sementes naquele país seja de $20 \%$, enquanto que no Brasil, a produção de melancia sem semente ainda é incipiente.

Um dos principais entraves à produção da melancia sem sementes é a germinação das sementes tetraplóides e triplóides, além do baixo vigor das plântulas originadas. A causa desses problemas ainda não está esclarecida (Yang e Sung, 1994). Alguns poucos estudos associam tal fato ao fraco desenvolvimento do embrião e à espessura do tegumento da semente como sendo os principais fatores que causam os baixos níveis de germinação em sementes de melancia poliplóides (Kihara, 1951). Na Embrapa Semi-Árido foram obtidas linhas tetraplóides para síntese de híbridos triplóides experimentais e tanto as tetraplóides, quanto os híbridos obtidos apresentaram problemas de germinação (Queiroz et al., 2001). No entanto, algumas cultivares comerciais apresentam problemas semelhantes e, geralmente, respondem aos tratamentos visando elevar a taxa de germinação e estabelecimento no campo.

Técnicas que induzem melhoria na qualidade fisiológica das sementes são importantes para aumentar o potencial de desempenho das mesmas e, por conseguinte, a uniformidade das plantas em condições de campo. A escarificação mecânica das sementes e a embebição das mesmas em água ou utilização de solução com substâncias promotoras de crescimento constitui em técnicas conhecidas há vários anos e que podem ser utilizadas com sucesso em sementes de melancia.

$\mathrm{O}$ uso de reguladores de crescimento pode favorecer o desempenho das plântulas, acelerando a velocidade de emergência de sementes de várias espécies. Segundo Khan et al. (1978), o uso de compostos químicos biologicamente ativos, como reguladores de crescimento, pode cessar ou diminuir o impacto de fatores adversos na qualidade e desempenho das sementes. $\mathrm{O}$ uso de giberelinas na fase de germinação pode melhorar a germinação de sementes de várias espécies, principalmente sob condições adversas (Cunha e Casali, 1989; Bevilaqua et al., 1993). As giberelinas desempenham papel chave na germinação de sementes, estando envolvidas tanto na superação da dormência como no controle de hidrólise das reservas, pela indução da síntese denovo da a-amilase, enzima responsável pela hidrólise do amido. O ácido giberélico, considerado ativador enzimático endógeno, promove a germinação (Levitt, 1974); a aplicação exógena deste promotor influencia o metabolismo proteíco, podendo dobrar a taxa de síntese de proteínas das sementes (McDonald e Khan, 1983). Segundo Salisbury e Ross (1991), na maioria das espécies, as giberelinas atuam no alongamento celular, fazendo com que a raiz primária rompa os tecidos que restringem seu crescimento, como o endosperma, o tegumento da semente ou estruturas do fruto.

Este trabalho teve como objetivo verificar o efeito de tratamentos pré-germinativos em sementes triplóides, tetraplóides e diplóides de melancia, sobre a germinação e o vigor das mesmas.

\section{MATERIAL E MÉTODOS}

O trabalho foi realizado no Laboratório de Análises de Sementes e em casa de vegetação do Departamento de Tecnologia e Ciências Sociais/ DTCS, Universidade do Estado da Bahia, Juazeiro - BA, em novembro de 2003.

Os tratamentos foram constituídos de 200 sementes diplóides de melancia da cv. Crimson sweet; 200 sementes tetraplóides da linhagem Charleston Tetra Número 3, obtidas por autofecundação em 2002 e 200 sementes triplóides oriundas de cruzamentos experimentais entre as linhagens tetraploidizadas e a cv. Crimson sweet.

Estas sementes foram submetidas aos tratamentos, controle; maceração em água $\left(25^{\circ} \mathrm{C}\right)$ por seis horas; escarificação mecânica com auxílio de lixa 200 + ácido 
giberélico $\left(\mathrm{GA}_{3}\right)$ na concentração de $200 \mathrm{mg} . \mathrm{L}^{-1}$, durante seis hora; escarificação mecânica; ácido giberélico $\left(\mathrm{GA}_{3}\right)$ na concentração de $200 \mathrm{mg} . \mathrm{L}^{-1}$, durante seis horas.

$\mathrm{O}$ teor de água das sementes foi determinado utilizandose duas repetições de 50 sementes, pelo método de estufa regulada a $105 \pm 3^{\circ} \mathrm{C}$ por 24 horas, de acordo com as Regras para Análise de Sementes (Brasil, 1992).

Após a realização dos tratamentos, as sementes foram submetidas ao teste de germinação, conduzido com quatro subamostras de 50 sementes, distribuídas em rolo de papel germitest, umedecido com quantidade de água equivalente a 2,5 vezes seu peso e mantidas em germinador a $25^{\circ} \mathrm{C}$ (Brasil, 1992). As avaliações foram feitas aos 5 e 12 dias após a semeadura e os resultados expressos em porcentagem média de plântulas normais por tratamento.

A avaliação do crescimento de plântulas foi realizada de acordo com metodologia proposta por Nakagawa (1999). Foram distribuídas 20 sementes sobre uma linha traçada no terço superior, no sentido longitudinal do substrato préumedecido. As sementes foram posicionadas com a extremidade da radícula para a parte inferior do papel. Foram confeccionados rolos semelhantes ao teste de germinação (Brasil, 1992) em quatro subamostras de 20 sementes por tratamento. Os rolos foram agrupados e colocados em sacos plásticos, verticalmente no interior do germinador a $25^{\circ} \mathrm{C}$ por 12 dias. Determinou-se o comprimento da raiz primária e da parte aérea das plântulas normais aos 5 e 12 dias após a semeadura.

A avaliação da emergência de plântulas foi realizada no interior de casa-de-vegetação coberta com sombrite $50 \%$, em bandejas plásticas com solo. As sementes previamente tratadas, conforme citado anteriormente, foram distribuídas nas bandejas, tendo 25 sementes por bandeja, totalizando 100 sementes por tratamento, em quatro repetições. Foram realizadas contagens diárias do número de plântulas emergidas até a estabilização da emergência das mesmas, considerandose emergidas aquelas que apresentavam os cotilédones expostos. Foram determinadas as porcentagens de emergência e o índice de velocidade de emergência de plântulas (IVE), segundo fórmula proposta por Maguire (1962).

O delineamento estatístico utilizado foi inteiramente casualizado em esquema fatorial $3 \times 5$, com quatro repetições e as médias foram comparadas pelo teste de Tukey ao nível de $5 \%$ de probabilidade.

\section{RESULTADOS E DISCUSSÃO}

Os resultados médios da germinação para os três tipos de sementes de melancia são apresentados na Tabela 1 . Observa-se que as sementes diplóides apresentaram superioridade para todos os tratamentos, quando comparadas às sementes triplóides e tetraplóides. As sementes tetraplóides foram estatisticamente semelhantes às sementes triplóides, diferindo-se apenas nas sementes do tratamento testemunha e escarificadas. Indicando que para este tipo de sementes, a maceração e imersão das sementes em $\mathrm{GA}_{3}$ podem ser considerados eficientes para aumentar a germinabilidade das sementes. As sementes diplóides apresentaram comportamento semelhante para todos os tratamentos, com germinação oscilando entre 90 e $95 \%$. Analisando-se as sementes tetraplóides, isoladamente, para os diferentes tratamentos empregados, verifica-se que não houve diferenças significativas entre os tratamentos. Nas sementes triplóides não se observou melhora das mesmas, nos diferentes tratamentos utilizados.

Com relação à primeira contagem da germinação, considerada como teste de vigor (Tabela 2), o comportamento dos três tipos de sementes seguiram mesmo padrão da germinação, ou seja, superioridade das sementes diplóides, seguidas das sementes triplóides e tetraplóides. Verifica-se também comportamento semelhante ao da germinação quando se analisa o tipo de sementes separadamente frente aos tratamentos empregados.

Sementes de Brachiaria plantaginea escarificadas e

TABELA 1. Porcentagem de germinação de sementes diplóides, triplóides e tetraplóides de melancia, submetidas aos tratamentos pré-germinativos.

\begin{tabular}{cccccc}
\hline \multirow{2}{*}{ Tipos de sementes } & \multicolumn{5}{c}{ Tratamentos } \\
\cline { 2 - 6 } & Testemunha & Maceração & Escarificação + GA $_{3}$ & Escarificação & GA 3 \\
\hline Diplóides & $95 \mathrm{aA}$ & $90 \mathrm{aA}$ & $93 \mathrm{aA}$ & $93 \mathrm{aA}$ & $91 \mathrm{aA}$ \\
Triplóides & $53 \mathrm{bA}$ & $32 \mathrm{bB}$ & $43 \mathrm{bAB}$ & $53 \mathrm{bA}$ & $34 \mathrm{bAB}$ \\
Tetraplóides & $32 \mathrm{cA}$ & $44 \mathrm{bA}$ & $42 \mathrm{bA}$ & $31 \mathrm{cA}$ & $33 \mathrm{bA}$ \\
\hline
\end{tabular}

Médias seguidas da mesma letra minúscula nas colunas e maiúscula nas linhas não diferem entre si pelo teste de Tukey a 5\% de probabilidade. 
TABELA 2. Resultados obtidos no teste de primeira contagem da germinação (\%) de sementes diplóides, triplóides e tetraplóides de melancia, submetidas aos tratamentos pré-germinativos.

\begin{tabular}{cccccc}
\hline \multicolumn{5}{c}{ Tratamentos } \\
\hline $\begin{array}{c}\text { Tipos de } \\
\text { sementes }\end{array}$ & Testemunha & Maceração & Escarificação + GA 3 & Escarificação & GA $_{3}$ \\
\hline Diplóides & $78 \mathrm{aA}$ & $50 \mathrm{aB}$ & $88 \mathrm{aA}$ & $92 \mathrm{aA}$ & $90 \mathrm{aA}$ \\
Triplóides & $55 \mathrm{bA}$ & $28 \mathrm{bB}$ & $42 \mathrm{bAB}$ & $53 \mathrm{bA}$ & $34 \mathrm{bAB}$ \\
Tetraplóides & $30 \mathrm{cA}$ & $42 \mathrm{bA}$ & $42 \mathrm{bA}$ & $28 \mathrm{cA}$ & $31 \mathrm{bA}$ \\
\hline
\end{tabular}

Médias seguidas da mesma letra minúscula nas colunas e maiúscula nas linhas não diferem entre si pelo teste de Tukey a 5\% de probabilidade.

mergulhadas em solução contendo $\mathrm{GA}_{3}$ na concentração de 0,5mmol. $\mathrm{L}^{-1}$ tiveram aumento em relação ao controle de, aproximadamente, 50 e $80 \%$ na germinação (quatorze dias após semeadura) e por ocasião da primeira contagem da germinação (sete dias após semeadura), respectivamente (Dantas et al., 2001).

Nagao e Furutani (1986) relataram aumento de 50\% na germinação de sementes de mamão papaya tratadas com $\mathrm{GA}_{3}$. Vários outros autores também verificaram o efeito benéfico de pré-embebição mediante a imersão direta das sementes em solução de ácido giberélico (Rosseto et al., 2000).

Na Tabela 3 são apresentados os resultados médios de crescimento de plântulas. Em geral, as sementes triplóides e tetraplóides foram significativamente semelhantes entre si e superiores às sementes diplóides. Analisando os efeitos dos tratamentos empregados, verifica-se para as sementes diplóides que o emprego da escarificação e do ácido giberélico separados e conjuntamente, beneficiou o crescimento de plântulas. De igual modo, aconteceu com as sementes tetraplóides, que tiveram maior crescimento de plântulas em função do uso da escarificação, do $\mathrm{GA}_{3}$ e da maceração. Já em sementes triplóides só o tratamento com maceração promoveu maior crescimento de plântulas, apesar de não diferir estatisticamente da testemunha. Aragão et al. (2001), utilizando tratamentos de $\mathrm{GA}_{3}$ combinado com Citocinina (PBA), obtiveram aumento no comprimento de raiz primária de plântulas de milho doce.

Quanto à emergência de plântulas em casa de vegetação, verificou-se novamente que as sementes diplóides apresentaram melhor desempenho em campo, seguidas das sementes híbridas (triplóides) e tetraplóides (Tabela 4). Comparando-se os tratamentos pré-germinativos empregados, verifica-se que os mesmos não surtiram efeitos satisfatórios, na emergência de plântulas (Tabela 4).

Por meio do índice de velocidade de emergência (Tabela 5) não foi possível detectar diferenças estatísticas entre os três tipos de sementes estudadas e os tratamentos empregados, exceto para as sementes triplóides, em que o

TABELA3. Resultados médios de crescimento de plântulas (cm) diplóides, triplóides e tetraplóides de melancia, submetidas aos tratamentos pré-germinativos.

\begin{tabular}{lcrccc}
\hline Tipos de & \multicolumn{5}{c}{ Tratamentos } \\
sementes & Testemunha & Maceração & Escarificação $+\mathrm{GA}_{3}$ & Escarificação & $\mathrm{GA}_{3}$ \\
\hline Diplóides & $1,05 \mathrm{cB}$ & $0,98 \mathrm{cB}$ & $4,17 \mathrm{bA}$ & $3,52 \mathrm{bA}$ & $4,67 \mathrm{bA}$ \\
Triplóides & $8,56 \mathrm{aAB}$ & $9,90 \mathrm{aA}$ & $7,03 \mathrm{aBC}$ & $6,42 \mathrm{aBC}$ & $5,42 \mathrm{bC}$ \\
Tetraplóides & $2,97 \mathrm{bB}$ & $6,71 \mathrm{aA}$ & $7,34 \mathrm{aA}$ & $5,33 \mathrm{abA}$ & $7,34 \mathrm{aA}$ \\
\hline
\end{tabular}

Médias seguidas da mesma letra minúscula nas colunas e maiúscula nas linhas não diferem entre si pelo teste de Tukey a 5\% de probabilidade.

TABELA 4. Porcentagem de emergência de plântulas de melancia diplóides, triplóides e tetraplóides, submetidas aos tratamentos pré-germinativos.

\begin{tabular}{lccccc}
\hline Tipos de & \multicolumn{5}{c}{ Tratamentos } \\
\cline { 2 - 6 } sementes & Testemunha & Maceração & Escarificação $+\mathrm{GA}_{3}$ & Escarificação & $\mathrm{GA}_{3}$ \\
\hline Diplóides & $82 \mathrm{aAB}$ & $92 \mathrm{aA}$ & $91 \mathrm{aA}$ & $82 \mathrm{aAB}$ & $59 \mathrm{aB}$ \\
Triplóides & $62 \mathrm{bA}$ & $59 \mathrm{aA}$ & $79 \mathrm{aA}$ & $70 \mathrm{abA}$ & $59 \mathrm{aA}$ \\
Tetraplóides & $63 \mathrm{abA}$ & $41 \mathrm{bAB}$ & $38 \mathrm{bBC}$ & $60 \mathrm{bAB}$ & $35 \mathrm{bC}$ \\
\hline
\end{tabular}

Médias seguidas da mesma letra minúscula nas colunas e maiúscula nas linhas não diferem entre si pelo teste de Tukey a 5\% de probabilidade. 
tratamento com ácido giberélico foi estatisticamente inferior aos demais. Aragão et al. (2001) verificaram que o ácido giberélico a $100 \mathrm{mg} . \mathrm{L}^{-1}$ promoveu aumento significativo em sementes de milho doce, tanto para o índice de velocidade de emergência quanto para a emergência de plântulas normais em campo.

TABELA 5. Índice de velocidade de emergência de plântulas de melancia diplóides, triplóides e tetraplóides, submetidas aos tratamentos pré-germinativos.

\begin{tabular}{cccccc}
\hline Tipos de & \multicolumn{5}{c}{ Tratamentos } \\
\cline { 2 - 6 } sementes & Testemunha & Maceração & Escarificação + GA $_{3}$ & Escarificação & $\mathrm{GA}_{3}$ \\
\hline Diplóides & $0,49 \mathrm{aA}$ & $0,65 \mathrm{aA}$ & $0,67 \mathrm{aA}$ & $0,59 \mathrm{aA}$ & $0,48 \mathrm{aA}$ \\
Triplóides & $0,46 \mathrm{aB}$ & $0,45 \mathrm{aB}$ & $0,69 \mathrm{aB}$ & $0,56 \mathrm{aB}$ & $0,40 \mathrm{aA}$ \\
Tetraplóides & $0,48 \mathrm{aA}$ & $0,34 \mathrm{aA}$ & $0,33 \mathrm{aA}$ & $0,42 \mathrm{aA}$ & $0,29 \mathrm{aA}$ \\
\hline
\end{tabular}

Médias seguidas da mesma letra minúscula nas colunas e maiúscula nas linhas não diferem entre si pelo teste de Tukey a 5\% de probabilidade.

\section{CONCLUSÃO}

O ácido giberélico e a escarificação, empregados separadamente e em associação, promovem maior crescimento de plântulas oriundas de sementes diplóides e tetraplóides e a maceração contribui para maior crescimento de plântulas tetraplóides.

\section{REFERÊNCIAS}

ARAGÃO, C.A.; LIMA, M.W.P.; MORAIS, O.M.; ONO, E.O.; BOARO, C.S.F.; RODRIGUES, J.D.; NAKAGAWA, J.; CAVARIANI, C. Fitorreguladores na germinação de sementes e no vigor de plântulas de milho super doce. Revista Brasileira de Sementes, Brasília, v.23, n.1, p.27-34, 2001.

BEVILAQUA, G.A.P.; PESKE, S.T.; SANTOS FILHO, B.G. Desempenho de sementes de arroz irrigado tratadas com regulador de crescimento. I. Efeito na emergência a campo. Revista Brasileira de Sementes, Brasília, v.15, n.1, p.75-80, 1993.

BRASIL. Ministério da Agricultura e Reforma Agrária. Regras para análise de sementes. Brasília: SNDA/ DNDV/CLAV, 1992. $365 \mathrm{p}$.

CUNHA, R.; CASALI, W.D. Efeito de substâncias reguladoras de crescimento sobre a germinação de sementes de alface (Lactuca sativa L.). Revista Brasileira de Fisiologia Vegetal, Brasília, v.1, n.2, p.121-132, 1989.

DANTAS, B.F.; ALVES, E.; ARAGÃO, C.A.; TOFANELLI, B.D; CORREAA, M.R.; RODRIGUES, J.D.; CAVARIANI, C.; NAKAGAWA, J. Germinação de sementes de capim-marmelada (Brachiaria plantaginea (link) hitchc.) tratadas com ácido giberélico. Revista Brasileira de Sementes, Brasília, v.23, n.2, p.27-34, 2001.

FAO Agricultural production, primary crops. Disponível em $<$ http//www.fao.org $>$. Acesso em: 10 fev. 2005.

FAO- FAOSTAT Situação da produção e área de hortaliças no Brasil, 2002. Database results. Disponível em: <http// www.fao.org>. Acesso em: 05 mar. 2005.

KHAN, A.A. Incorporation of bioactive chemicals into seeds to alleviate environmental stress. Acta Horticulturae, Wageningen, v.83, n.2 p.2255-2264, 1978.

KIHARA, H. Triploid watermelon. Journal American Society Horticultural Science, St. Joseph , v.58, n.1, p.217-230, 1951.

LEVITT, J. Introduction to plant physiology. 2. ed. Saint Louis: The C.V. Mosby Company, 1974. 447p.

MAGUIRE, J.A. Speed of germination aid in selection and evaluation for seedling emergence and vigor. Crop Science, Madison, v.2, n.2, p.176-177, 1962.

McDONALD, M.D.; KHAN, A.A. Acid scarification and protein synthesis during seed germination. Agronomy Journal, Alexandria, v.2, n.75, p.111-114, 1983

NAGAO, M.A.; FURUTANI, S.C. Improving germination of papaya seed by density separation, potassium nitrate, and gibberelic acid. HortScience, Alexandria, v.21, n.6, p.1439-1440, 1986.

NAKAGAWA, J. Testes de vigor baseados no desempenho das plântulas. In: KRZYZANOWSKI, F.C.; VIEIRA, R.D.; FRANÇANETO, J.B. (Ed.) Vigor de sementes: conceitos e testes. Londrina: ABRATES, 1999. p.2-21.

QUEIRÓZ, M. A.; FRANÇA, F.F.; COSTA, N.D.; DIAS, R.C.S.; ARAÚJO, H.M. Desempenho de híbridos triplóides experimentais de melancia no Vale do Submédio São Francisco. Horticultura Brasileira, Brasília, v. 19. Suplemento, CD-ROM.

ROSSETO, C.A.V.; CONEGLIAN, R.C.C.; NAKAGAWA, J.; SHIMIZU, M.K. \& MARIN, V.A. Germinação de sementes de maracujá-doce (Passiflora alata Dryand) em função de tratamento pré-germinativo. Revista Brasileira de Sementes, Brasília, v.22, n.1, p.247-252, 2000.

SAlisBURY, F.B.; ROSS, C.W. Plant Physiology. Belmont: Wadsworth, 1991. 682p.

YANG, M.L.; SUNG, F.M.J. The effect of suboptimal temperature on germination of triploid watermelon seeds of different weights. Seed Science and Technology, Zürich, v.22, n.1, p.485-493, 1994. 